\title{
Esquistossomose hepática como achado ocasional de figado de doador para transplante
}

\section{Hepatic schistosomiasis as an occasional finding in a transplanted liver}

\author{
Ivelise R.C Brasil' ${ }^{1}$, Larissa R. Nepomuceno², Rodrigo T.. Schüller ${ }^{3}$, Ticiana M.Esmeraldo4, Romero M. Esmeraldo4,
} Ronaldo M. Esmeraldo ${ }^{4}$

\begin{abstract}
RESUMO
Introdução: A prevalência de cirrose criptogênica varia de 5\% a 30\% dos pacientes cirróticos nas séries históricas. $O$ transplante hepático representa a única opção em reverter a insuficiência hepatica e suas complicações em pacientes cirróticos em estágio avançado. A esquistossomose mansônica no Brasil é um problema endêmico de saúde pública,particularmente na região nordeste do país.Apresenta-se relato de caso de paciente do sexo masculino admitido ao Hospital Geral de Fortaleza, Ceará , Brasil, com cirrose criptogênica classificada como Child Turcotte-Pugh C, com MELD 25, submetido a transplante hepático com fígado de doador portador de esquistossomose como achado ocasional da biópsia padrão. Foi revisada a história clínica e exame físico na admissão, resultados de exames laboratoriais e dados do seguimento clínico.Como conclusão, as infecções parasitárias em órgãos sólidos transplantados tem aumentado nos últimos anos. É muito importante realizar o controle da qualidade dos órgãos e tecidos utilizados em transplantes, assim como desenvolver técnicas de diagnóstico, tratamento e profilaxia, especialmente em transplante hepático, em vista da alta prevalência de infecções parasitárias em nosso país, com intuito de prevenir outras co-morbidades e aumentar a sobrevida dos pacientes transplantados. Em regiões endêmicas, os potenciais doadores de receptores que têm esquistossomose ativa devem ser preventivamente tratados.
\end{abstract}

Palavras-chave: Cirrose Hepática. Transplante Hepático. Esquistossomose Mansônica.

\section{Introdução}

O termo cirrose criptogênica significa cirrose hepática de etiologia indeterminada..$^{1}$ A prevalência de cirrose criptogênica varia de 5 a $30 \%$ dos pacientes cirróticos. ${ }^{2} \mathrm{O}$ transplante hepático representa a única opção para reverter a insuficiência hepática e suas complicações nos pacientes com cirrose em estágio avançado.

A esquistossomose mansônica vem se estabelecendo como um sério problema de Saúde Pública, afetando cerca de 200 milhões de pessoas em várias regiões do mundo. No Brasil, a doença é considerada endêmica, apresentando aproximadamente seis milhões

1. Professora adjunta Universidade Estadual do Ceará, chefe serviço transplante hepático do Hospital Geral de FortalezaCE

2. Aluna do 5‥ Ano do curso de medicina da Universidade Estadual do Ceará

3. Patologista do serviço de transplante Hepático do Hospital Geral de Fortaleza-CE

4. Médicos do serviço de transplante Hepático do Hospital Geral de Fortaleza

Correspondência:

E-mail:ivesbrasil@ hotmail.com

Artigo recebido em 24/05/2013 Aprovado para publicação em 28/06/2013 
de indivíduos infectados. ${ }^{3,4}$ Dentre as regiões geográficas do país, a Nordeste apresenta a maior casuística da enfermidade.

Relata-se o caso de um paciente portador de cirrose hepática criptogênica, que foi submetido a transplante hepático e recebeu, ocasionalmente, fígado de doador portador de esquistossomose mansônica.

\section{Relato do Caso}

Paciente do sexo masculino, 53 anos, natural de Santa Quitéria e procedente de Fortaleza-CE, procurou atendimento médico há cerca de quatro anos com queixas de dor abdominal em aperto, progressiva, que passou a ser constante em flanco esquerdo com irradiação para fossa ilíaca esquerda e hipogástrio, associado a urgência evacuatória e miccional, tenesmo, além de diarréia aquosa sem muco ou sangue (várias vezes ao dia). Negava náuseas, vômitos, febre, perda de peso, acolia fecal, colúria, melena e hematoquezia. Refere ainda astenia, prurido cutâneo generalizado, além de parestesias em membros inferiores (região pré-tibial e dorso dos pés).

Refere que foi submetido a uma colescistectomia videolaparoscópica há 17 anos. Também relata ter realizado tratamento para hanseníase de forma irregular há sete anos. Nega outras comorbidades.

Nega tabagismo ou uso de drogas ilícitas. Refere etilismo ( 24 unidades de cerveja por fim de semana durante 15 anos), tendo deixado o hábito há nove anos.

Exames de função hepática revelaram aumento da fosfatase alcalina- FA(1324mg/dl) e da gamaGT $(369 \mathrm{mg} / \mathrm{dl})$, bilirrubinas total $(1,75)$ e direta $(1,20 \mathrm{mg} / \mathrm{dl})$. Realizou investigação com endoscopia digestiva alta (EDA) e retossigmoidoscopia, que revelaram varizes esofágicas e varizes hemorroidárias grau I, respectivamente. A colangiorressonância mostrou afilamento abrupto de colédoco distal. Já a ultrassonografia abdominal revelou fibrose periportal, esplenomegalia e ascite. Foi solicitada também biópsia hepática, cujo exame citopatológico (17/04/2007) concluiu se tratar de hepatopatia fibrosante de tendência cirrosante. As sorologias para esquistosomose, hepatites $\mathrm{B}$ e $\mathrm{C}$ e HIV resultaram negativas.

Evoluiu com manifestações de encefalopatia hepática e circulação colateral em abdome. Esteve internado várias vezes devido a complicações da doença hepática, como diarréia crônica persistente, ascite com drenagem espontânea por hérnia umbilical, um episódio de hematêmese importante, além de colite pseudomembranosa, celulite em membro inferior e infecção urinária.

Submeteu-se a cirurgia de transplante hepático há um ano, com classificação Child-Pugh C e MELD 25. O Doador não apresentava nenhuma alteração clínica e laboratorial assim como o fígado e baço eram normais durante a cirurgia de captação do órgão. Realizada biópsia padrão pré-perfusão, somente analisada após o transplante, a qual mostrou no laudo histopatológico a presença de granulomas em vários estágios evolutivos, e alguns gigantes do tipo corpo estranho centrados por restos de ovos de $S$. mansoni, vistos no lóbulo e em tratos portais, sem fibrose, revelando a presença de esquistossomose hepática e ausência de esteatose. (Figuras 1, 2, 3)

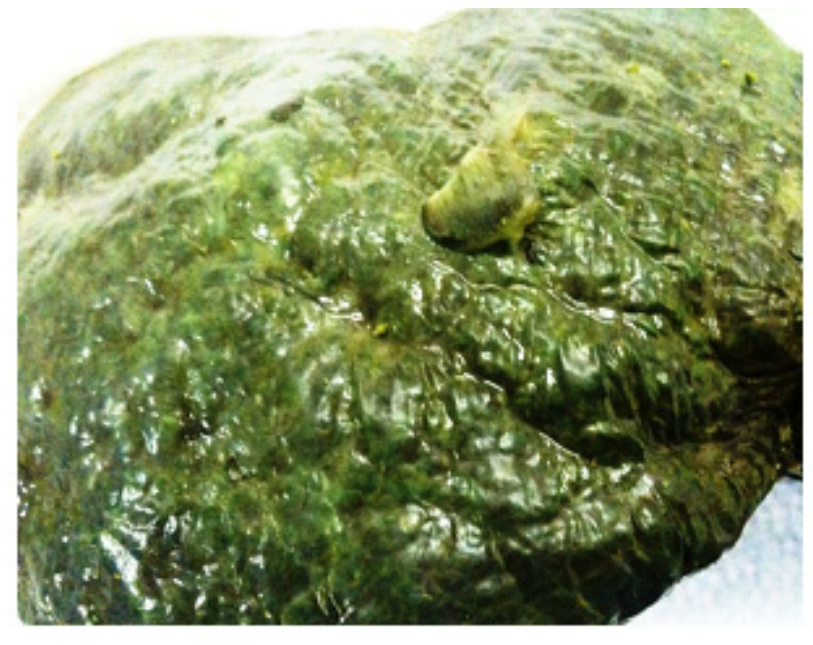

Figura1: Aspecto macroscópico do fígado explantado (receptor): superfície externa de aspecto nodular e uma coloração esverdeada, indicando colestase.

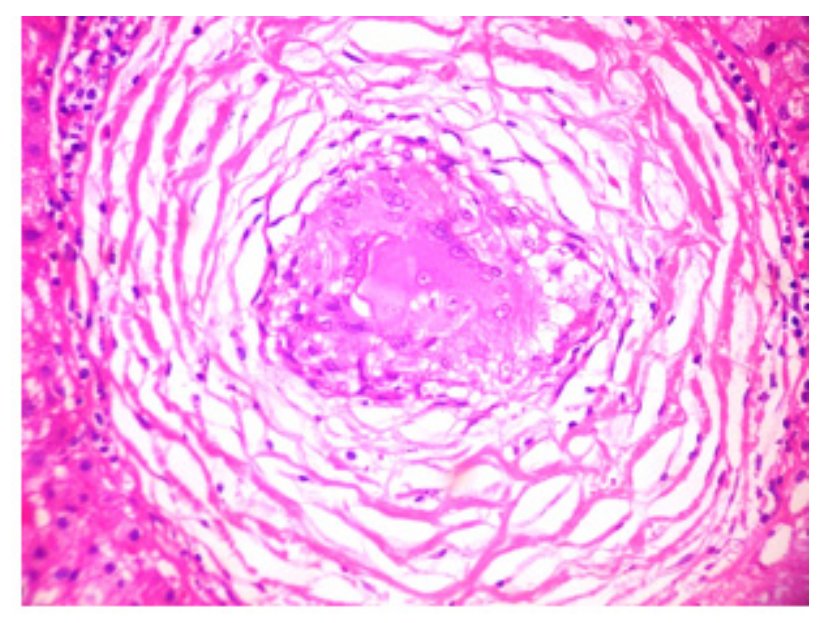

Figura 2: Microscopia panorâmica do fígado do doador mostra tecido hepático com múltiplos granulomas (H\&E 50x) 


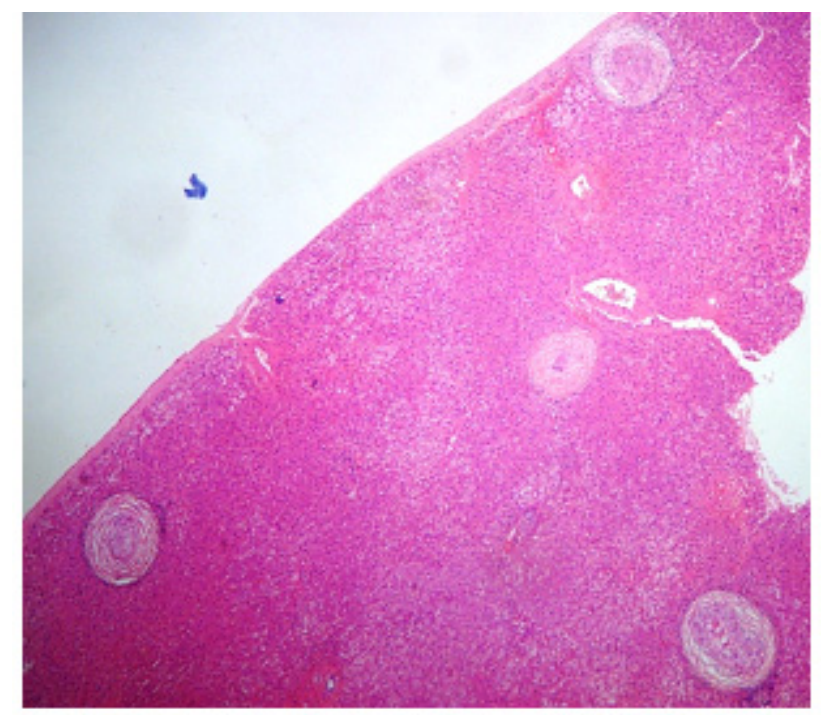

Figura 3: Microscopia do fígado do doador mostra presença de granuloma e, no centro, parte de ovo de esquistossoma (H\&E 400x).

Evoluiu no primeiro dia pós-operatório apenas com plaquetopenia (98.300) e pico de TGO 781 e TGP 582 , normalizadas no $7^{\circ}$. Pós-operatório. A Ultrassonografia com Doppler abdominal pós-transplante mostrou ausência de alterações significativas, apenas ascite de pequeno volume e esplenomegalia leve. A terapia imunossupressora foi iniciada no $2^{\circ}$ dia pós-operatório, com Tracrolimus, logo após associado Prednisona e Mycofenolato sódico No $5^{\circ}$ dia pós-operatório, evoluiu com icterícia 4+/4+, vômitos persistentes, anasarca, edema de membros inferiores $(3+/ 4+)$, turgência jugular, anúria por 12 horas, cefaléia holocraniana e desorientação. Foi solicitada Ultrassonografia (USG) abdominal para descartar complicações vasculares ou biliares, a qual foi normal. A Colangiorressonância também não acusou alterações na via biliar.

Já no $6^{\circ}$ dia pós-operatório, evoluiu com confusão mental e sonolência (15 pontos na escala de coma de Glasgow) além da elevação das bilirrubinas sem elevação de transaminases. Houve ainda drenagem de líquido ascítico sero-sanguinolento pela ferida operatória, que resultou bacterioscopia e cultura negativas. Foi tratado por pulsoterapia três dias metilprednisolona $500 \mathrm{mg}$ ev.

A partir do $7^{\circ}$ dia pós-operatório, houve melhora clínica importante. Foi realizada profilaxia para citomegalovírus (CMV) com Ganciclovir. A sorologia para esquistossomose no $15^{\circ}$ dia pós-transplante resultou negativa.
O paciente recebeu alta hospitalar após 19 dias de internação, com a melhora dos níveis de bilirrubina e com o quadro clínico estável, manifestando apenas icterícia leve. Permaneceu estável em todo o seguimento pós-operatório sem novas internações.

O tratamento anti-parasitário foi instituído (Praziquantel) após a alta e não houve manifestação da doença esquistossomótica até o presente momento, confirmada por biópsia protocolar controle que não mostrou sinais da doença.

\section{Discussão}

A cirrose hepática é definida como um processo crônico, progressivo e difuso, caracterizado por fibrose e nódulos estruturalmente anormais no fígado. O termo cirrose criptogênica significa cirrose hepática de etiologia indeterminada. ${ }^{1}$ A prevalência de cirrose criptogênica varia de 5 a $30 \%$ dos pacientes cirróticos em seguimentos prévios. ${ }^{2}$

A cirrose criptogênica é diagnosticada quando uma avaliação extensa exclui etiologias reconhecíveis de doença hepática crônica, como hepatites virais, hepatites auto-imunes, esteato-hepatite não-alcoólica, doença metabólica hepática, infecção por citomegalovírus ou vírus Epstein-Barr, drogas hepatotóxicas, doença de Wilson, doenças do trato biliar, obstrução fluxo venoso, deficiência de -1-antitripsina, diabetes descompensada, disfunção da tireóide, abuso de álcool, sobrecarga de ferro, obesidade mórbida e outras doenças sistêmicas. ${ }^{5}$

O transplante hepático representa a única opção para reverter a insuficiência hepática e suas complicações nos pacientes com cirrose em estágio avançado. Ainda que o transplante seja um procedimento exigente, a maioria dos pacientes retorna a uma qualidade de vida próxima do normal dentro de três a seis meses. Isso é possível principalmente pelas melhorias na terapia de imunossupressão em termos de tolerância e eficácia. ${ }^{6}$ Contudo, devido à escassez de doadores cadáver, são necessários critérios drásticos para a seleção de potenciais candidatos ao transplante. O transplante é geralmente considerado após o primeiro episódio de descompensação da cirrose. A ocorrência de ascite, peritonite bacteriana espontânea ou encefalopatia espontânea estão associados a um declínio significativo na expectativa de $\operatorname{vida}^{6}$, tendo o paciente no caso relatado apresentado mais de uma dessas ocorrências. 
Em 2006, o Ministério da Saúde modificou os critérios de distribuição de fígado de doadores cadáveres para transplante, implantando o critério de gravidade de estado clínico do paciente ${ }^{7}$. No caso apresentado, o paciente apresentava MELD ( Model for End-stage Liver Disease ) de 25.

A esquistossomose mansônica é uma doença parasitária, causada pelo trematódeo Schistosoma mansoni. No Brasil, estima-se que aproximadamente 25 milhões de pessoas estejam expostas ao risco de contrair a doença (Ministério da Saúde, 2010). No presente caso, relata-se uma forma não-habitual de risco de se adquirir a doença, através da recepção de um fígado esquistossomótico via transplante.

A forma hepatoesplênica da esquistossomose mansônica é clinicamente mais severa, manifestada por hepatomegalia, fibrose hepática e hipertensão portal, com o eventual desenvolvimento de circulação colateral porto-sistêmica. ${ }^{8} \mathrm{~A}$ infecção crônica é causa de morbimortalidade significante, resultado da formação de granulomas no intestino e no fígado. O processo de fibrose hepática resultante pode levar à hipertensão portal que pode eventualmente complicar com esplenomegalia, varizes esofágicas, hematêmese e levar à morte. ${ }^{8}$

A reação granulomatosa devido à presença de ovos do parasito no fígado pode induzir à inflamação perisinusoidal e fibrose periportal (fibrose de symmers). ${ }^{9}$ Essa peripileflebite granulomatosa provoca uma retração da cápsula hepática (cápsula de Glisson) pelo fibrosamento dos espaços porta e ma- nutenção da integridade do parênquima hepático. Dessa forma se nota a fibrose do órgão, cuja retração de sua cápsula em numerosos pontos provoca a formação de saliências ou lobulações. ${ }^{10}$ No órgão do doador do caso descrito, porém, não se detectou a presença de fibrose, manifestando aparentemente uma forma não-grave de esquistossomose hepática.

Existem dois medicamentos disponíveis para tratamento de pacientes portadores de S. mansoni: o praziquantel e a oxaminiquina. Os dois medicamentos se equivalem quanto à eficácia e a segurança. Atualmente, o praziquantel é a droga de escolha, em função da melhor relação custo/benefício. Os casos graves geralmente requerem internação hospitalar e tratamento cirúrgico. ${ }^{11}$

\section{Conclusão}

As infecções parasitárias em órgãos sólidos transplantados tem aumentado nos últimos anos . É de fundamental importância um controle de qualidade rigoroso de órgãos e tecidos transplantados, assim como um aprimoramento das técnicas de diagnóstico, tratamento e profilaxia em transplantes, em especial no transplante hepático, em vista de um alto número de infecções vigentes em nosso país, visando evitar o desenvolvimento de outras co-morbidades e aumentar a sobrevida dos pacientes submetidos a transplante. Em regiões endêmicas, os potenciais doadores de receptores que têm esquistossomose ativa devem ser preventivamente tratados.

\begin{abstract}
Introduction: The prevalence of cryptogenic cirrhosis ranges from $5 \%$ to $30 \%$ of cirrhotic patients in past series (CADWELL et al, 1999). Liver transplantation represents the only option to revert the hepatic insufficiency and its complications in cirrhotic patients in advanced stage. In Brazil, Mansonic Schistosomiasis is a public health problem and endemic disease, particularly in the Northeast of the country. Methods: Case report of a male patient, admitted to Hospital Geral de Fortaleza, Ceará, Brazil, with cryptogenic hepatic cirrhosis, classified as Child-Turcotte-Pugh C, with a MELD of 25, submitted to a liver transplantation, and found to have schistosomal hepatic disease on biopsy report. We reviewed the patient's medical history and physical examination on admission, prescription, results of laboratory tests and follow up data. Survey of the literature in national and international scientific journals helped in collecting information on this disease.

Conclusions: Parasitic infections in solid organ transplant has increased in the recent years. It is very important to keep a strict control of the quality of the organs and tissues used in transplantations, as well as an improvement in diagnosis, treatment and prophylaxis techniques, especially in liver transplantation, in view of a high prevalence of parasitic infections in our country, in order to prevent the development of other comorbidities, and to increase the survival of transplanted patients. In endemic countries, potential donors or recipients who have active schistosomal infection should be preventively treated.
\end{abstract}

Key Words: Liver Cirrhosis. Liver Transplantation. Schistosomiasis mansoni. 


\section{Referências}

1- Desai HG. Cryptogenic Cirrhosis : A vanishing entity. JAPI. 2009; 57: 751-5.

2- Caldwell SH, Oelsner DH, lezzoni JC, Hespenheide EE, Battle $\mathrm{EH}$, Driscoll CJ. Cryptogenic cirrhosis: clinical characterization and risk factors for underlying disease. Hepatology. 1999; 29:664-9.

3- Katz N,; Peixoto SV. Análise crítica da estimativa do número de portadores de esquistossomose mansoni no Brasil. Rev Soc Bras Med Trop. 2000; 33:303-8.

4- Bina JC, Prata A. Esquistossomose na área hiperendêmica de Taquarendi. I - Infecção pelo Schistosoma mansoni e formas graves. Rev Soc Bras Med Trop. 2003; 36: 211-6.

5- Bokharaei-Salim F, Keyvani H, Monavari SH, Alavian SM, Madjd $\mathrm{Z}$, Toosi MN Mohammad Alizadeh AH. Occult hepatitis $\mathrm{C}$ virus infection in Iranian patients with cryptogenic liver disease. $J$ Med Virol. 2011; 83: 989-95.

6- Francoz C, Belghiti J, Durand F. Indications of liver transplantation in patients with complications of cirrhosis. Best Pract Res Clin Gastroenterol. 2007;21:175-90.
7- BRASIL. Ministério da Saúde - Portaria № 1.160 De 29 de Maio de 2006. Modifica os critérios de distribuição de fígado de doadores cadáveres para transplante, implantando o critério de gravidade de estado clínico do paciente.

8- Bica I, Hamer DH, Stadecker MJ. Hepatic Schistosomiasis. Infect dis clin North Am. 2000; 14: 583-604.

9- Ross AG, Bartley PB, Sleigh AC, Olds GR, Li Y, Williams GM McManus DP. Schistosomiasis. N Engl J Med. 2002; 346):1212-20.

10- Zilton Andrade, Sônia Andrade. Patologia da Esquistossomose Hepatoesplênica. In.: Aspectos peculiares da infeccção por Schistosoma mansoni, Salvador - Centro Editorial e Didático da UFBa - 1984.

11- BRASIL. Ministério da Saúde. Secretaria de Vigilância em Saúde. Departamento de Vigilância Epidemiológica. Guia de doenças infecciosas e parasitárias 8 a ed. revista -Brasília DF-2010. 